\title{
Backbone and side chain NMR assignments for the intrinsically disordered cytoplasmic domain of human neuroligin-3
}

\author{
Kathleen Wood · Aviv Paz $\cdot$ Klaas Dijkstra • \\ Ruud M. Scheek • Renee Otten • Israel Silman • \\ Joel L. Sussman • Frans A. A. Mulder
}

Received: 25 March 2011/Accepted: 23 May 2011/Published online: 7 June 2011

(c) The Author(s) 2011. This article is published with open access at Springerlink.com

\begin{abstract}
Neuroligins act as heterophilic adhesion molecules at neuronal synapses. Their cytoplasmic domains interact with synaptic scaffolding proteins, and have been shown to be intrinsically disordered. Here we report the backbone and side chain ${ }^{1} \mathrm{H},{ }^{13} \mathrm{C}$ and ${ }^{15} \mathrm{~N}$ resonance assignments for the cytoplasmic domain of human neuroligin 3 .
\end{abstract}

Keywords Intrinsically disordered protein .

Neural cell adhesion - PDZ-binding domain .

Cholinesterase-like adhesion molecule

K. Wood · K. Dijkstra $\cdot$ R. M. Scheek $\cdot$ R. Otten ·

F. A. A. Mulder ( $\square)$

Department of Biophysical Chemistry, Groningen Biomolecular Sciences and Biotechnology Institute, University of Groningen,

Nijenborgh 7, 9747 AG Groningen, The Netherlands

e-mail: f.a.a.mulder@rug.nl

URL: www.protein-nmr.org

\section{A. Paz $\cdot$ I. Silman}

Department of Neurobiology, Weizmann Institute of Science, Rehovot, Israel

\author{
A. Paz · J. L. Sussman \\ Department of Structural Biology, Weizmann Institute \\ of Science, Rehovot, Israel
}

Present Address:

K. Wood

Bragg Institute, Australian Nuclear Science and Technology

Organisation, Menai, NSW, Australia

\section{Present Address:}

A. Paz

Department of Physiology, David Geffen School of Medicine, University of California, Los Angeles, CA 90095-1751, USA

\section{Biological context}

Synaptic adhesion proteins bridge pre- and postsynaptic specializations at neuronal synapses. As well as providing mechanical bridging, they participate in formation, function, and plasticity of such synapses (Dalva et al. 2007). Cholinesterase-like (ChE-like) adhesion molecules (CLAMs) are a class of neuronal cell adhesion molecules that are characterised by an extracellular $\mathrm{N}$-terminal domain displaying sequence homology to acetylcholinesterase (although lacking catalytic activity), a single transmembrane segment, and a small intracellular C-terminal domain (Gilbert and Auld 2005).

Neuroligins (NLs) are a family of CLAMs, of which four isoforms have been identified (Baudouin and Scheiffele 2010), that are embedded in the postsynaptic membrane. Their ChE-like extracellular domains interact with their presynaptic partners, the neurexins.

The intracellular domain of human NL3 (hNL3-cyt) is disordered in the absence of binding partners (Paz et al. 2008), and has been shown to interact with several scaffolding proteins, including PSD-95 (Irie et al. 1997), via a C-terminal PDZ-recognition motif.

Mutations in NL3 and NL4 have been shown to be associated with autism (Jamain et al. 2003), and the neurexin-NL-PSD95 interaction has been implicated in ischemia ( $\mathrm{Li}$ et al. 2007). Conformational characterization of the disordered cytoplasmic domains of the NLs, and of their interactions with partner proteins, is important for understanding structural and functional features of synaptic junctions, and may also lead to possible targets for the treatment of neurological disorders.

Here we report the backbone and side-chain NMR resonance assignments of hNL3-cyt. 


\section{Methods and experiments}

Expression and purification of uniformly labelled hNL3-cyt were performed as described previously ( $\mathrm{Paz}$ et al. 2008). The NMR sample contained $1 \mathrm{mM}$ of uniformly ${ }^{13} \mathrm{C},{ }^{15} \mathrm{~N}$ enriched protein in a solution of $5 \mathrm{mM}$ dithiothreitol (DTT)/20 mM phosphate, $\mathrm{pH} 6.0$, containing $0.1 \mathrm{mM}$ DSS (2,2-Dimethyl-2-silapentane-5-sulfonic acid). Sodium azide was added to $0.02 \%(\mathrm{w} / \mathrm{v})$, and $\mathrm{D}_{2} \mathrm{O}$ to $7 \%(\mathrm{v} / \mathrm{v})$.

All experiments were performed at $25^{\circ} \mathrm{C}$ on a Varian Unity Inova $600 \mathrm{MHz}$ spectrometer, equipped with a triple-resonance room temperature probehead and single-axis pulsed field gradient capabilities.

2D $\left[{ }^{1} \mathrm{H}-{ }^{15} \mathrm{~N}\right]-\mathrm{HSQC}, \quad 3 \mathrm{D} \quad \mathrm{HNCA} / \mathrm{HN}(\mathrm{CO}) \mathrm{CA}, \quad 3 \mathrm{D}$ $\mathrm{HN}(\mathrm{CA}) \mathrm{CO} / \mathrm{HNCO}, 3 \mathrm{D} \mathrm{HNCACB} / \mathrm{CBCA}(\mathrm{CO}) \mathrm{NH},{ }^{15} \mathrm{~N}-$ edited NOESY-HSQC (Sattler et al. 1999), 3D HNN/ $\mathrm{HN}(\mathrm{C}) \mathrm{N}$ (Panchal et al. 2001), and 3D (HN)CO(CO)NH (Grzesiek and Bax 1997) and projection-reconstruction 4D (HA)CACONH (Coggins et al. 2004) experiments were used to obtain the sequential backbone resonance assignment. Side chain assignments were achieved with 3D COCAH (Dijkstra et al. 1994), 3D ${ }^{15} \mathrm{~N}$-edited TOCSY-HSQC (Marion et al. 1989), 3D HC(C)H-TOCSY (Bax et al. 1990), and 3D (H)CC(CO)NH-TOCSY (Logan et al. 1993) experiments.

Data were processed with the NMRPipe/NMRDraw software package (Delaglio et al. 1995), and analyzed using the program Sparky (Goddard and Kneller 2004). All chemical shifts are referenced to DSS according to IUPAC recommendation (Markley et al. 1998).

\section{Assignments, data deposition and intrinsic exchange rates}

Figure 1 illustrates the 2D $\left[{ }^{1} \mathrm{H}-{ }^{15} \mathrm{~N}\right]-\mathrm{HSQC}$ spectrum and assignments of the amide resonances of hNL3-cyt; its unfolded nature is evident from the small dispersion in the amide proton resonances. The construct contains 139 residues, the first 10 of which are a 6xHis-tag, followed by a short linker sequence (see also Fig. 4). Following a standard sequential assignment procedure, 98\% of the observable backbone ${ }^{1} \mathrm{H},{ }^{15} \mathrm{~N}$ and ${ }^{13} \mathrm{C}$ resonances were assigned (excluding the tag). The observable ${ }^{1} \mathrm{H} /{ }^{15} \mathrm{~N}$ pairs are displayed in Fig. 1, labeled by their one-letter amino acid code and residue number. Considering only aliphatic ${ }^{1} \mathrm{H}$ and ${ }^{13} \mathrm{C}$ atoms, side chain assignments are complete to $92 \%$.

The resonance assignments were deposited in the $\mathrm{Bi}$ oMagResBank (http://www.bmrb.wisc.edu/) under accession number 17290.

To understand whether the absence of some backbone amide proton resonances in our experiments was due to fast
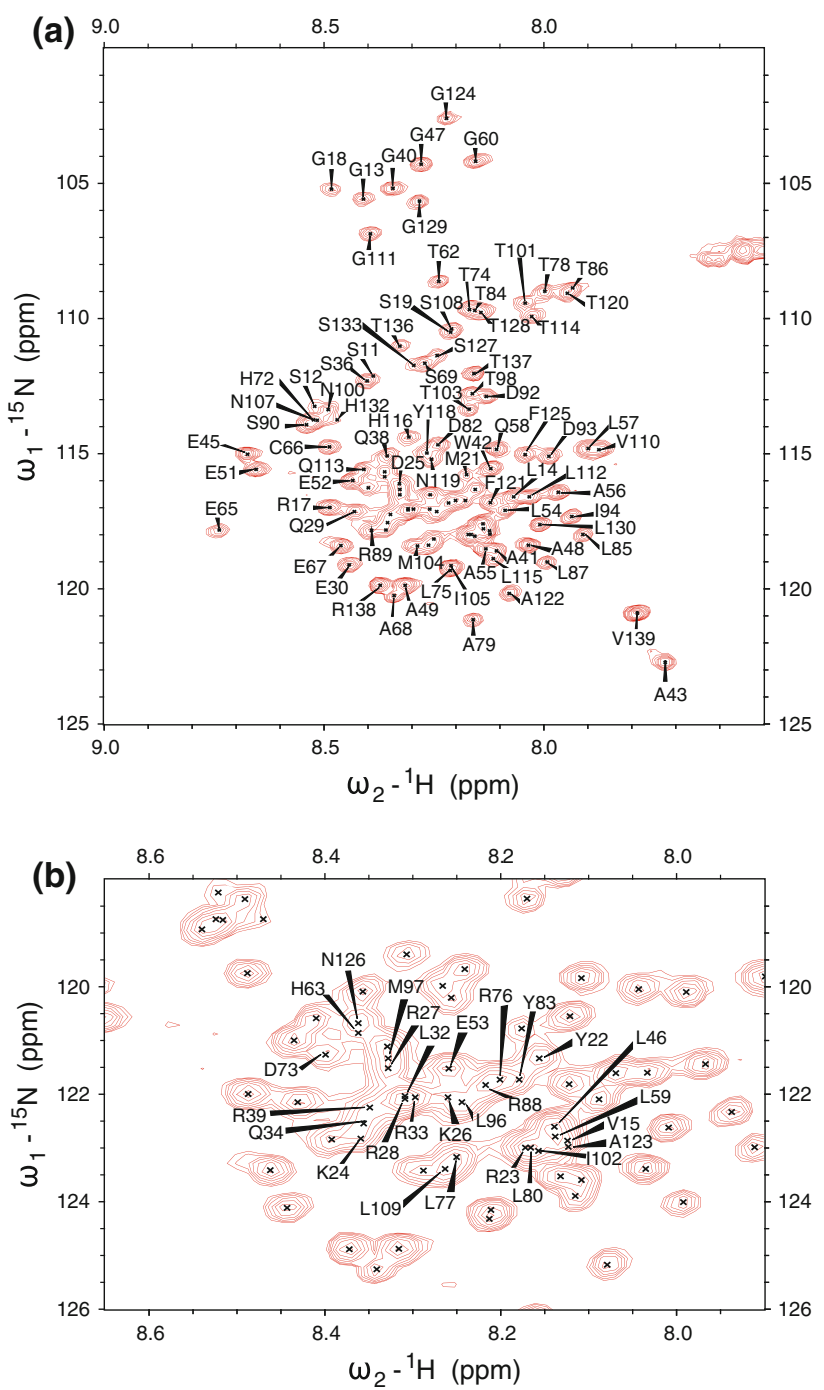

Fig. $12 \mathrm{D}\left[{ }^{15} \mathrm{~N}-{ }^{1} \mathrm{H}\right]-\mathrm{HSQC}$ spectrum of hNL3-cyt at $600 \mathrm{MHz}$ and $25^{\circ} \mathrm{C}$

exchange with the solvent, intrinsic exchange rates were calculated (Bai et al. 1993) using the program Sphere (http://www.fccc.edu/research/labs/roder/sphere/sphere. html) and these values are plotted in Fig. 2. The data show that in all cases where the amide proton resonance was not assigned (for residues H20, H64, H134, and S135), intrinsic exchange rates faster than $15 \mathrm{~s}^{-1}$ are predicted.

\section{Secondary structure prediction}

Considering charge and hydrophobicity in a so-called Uversky plot (Uversky et al. 2000), hNL3-cyt was found to lie very close to the boundary between proteins predicted to be unfolded and folded (Zeev-Ben-Mordehai et al. 2003). A bioinformatics analysis using several predictors had been performed earlier for hNL3-cyt (Paz et al. 2008). It 


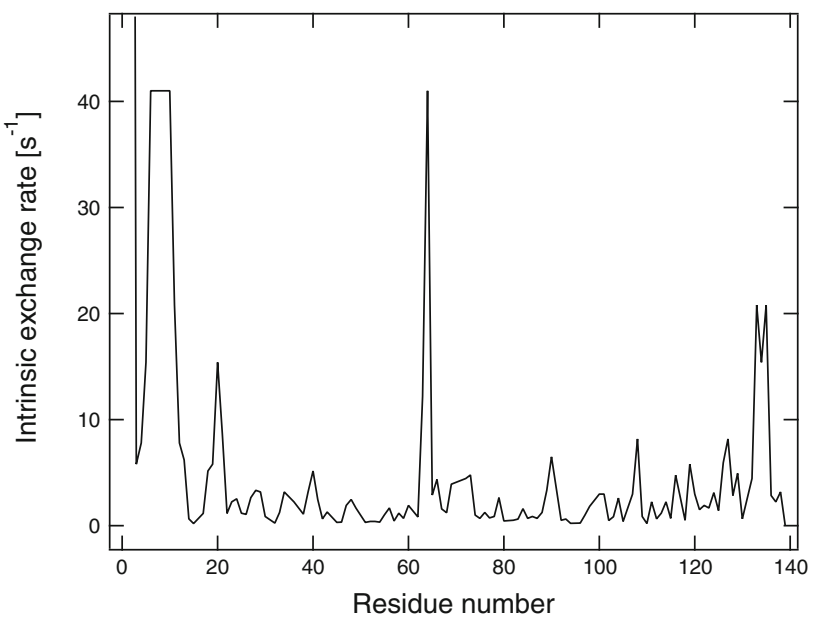

Fig. 2 Predicted intrinsic exchange rates of amide protons with solvent for hNL3-cyt at $\mathrm{pH} 6.0,25^{\circ} \mathrm{C}$. pKa values of 4.0 for Asp, 4.4 for Glu, and 6.75 for His side chains were used. Residues H20, H64, $\mathrm{S} 133, \mathrm{H} 134$, and $\mathrm{S} 135$ have predicted exchange rates faster than $15 \mathrm{~s}^{-1}$; Except for S133, which is broadened, their amide resonances are not visible in the spectra

predicted that the N-terminal section (residues 1-70) is completely disordered, while the C-terminal segment is predicted to be somewhat more ordered, depending on the predictor used. Here we use two bioinformatic methods to predict structural propensity in hNL3-cyt: PONDR ${ }^{\circledR}$ (Romero et al. 2001) and Jpred 3 (Cole et al. 2008), which consider sequence information alone. These results were compared to secondary structural propensity (SSP) scores (Marsh et al. 2006), derived from the experimental chemical shift data.

PONDR $^{\circledR}$ predicts that $73 \%$ of hNL3-cyt is disordered, consistent with the small dispersion of amide chemical shifts measured by NMR. PONDR scores of the sequence are displayed in Fig. 3, where a score between 0.5 and 1 indicates disorder, and a score between 0 and 0.5 indicates order. The figure shows that the first 75 residues are predicted to be disordered, and that order and disorder alternate in the remainder of the sequence. Specifically, two ordered stretches are predicted, viz., residues 76-92 and 111-128.

Secondary structure prediction for hNL3-cyt was also performed based on sequence similarity using Jpred 3. 88\% of the residues are predicted to be disordered by the Jpred 3 algorithm. As seen in Fig. 4, three short helical stretches are predicted, residues 25-29, 53-60 and 84-86.

A prediction of secondary structural propensity was also performed based on chemical shift analysis using SSP. The analysis used measured chemical shifts of $\mathrm{C}^{\alpha}, \mathrm{C}^{\beta}$ and $\mathrm{H}^{\alpha}$ atoms, and an averaging window of five residues (Fig. 5). A positive SSP score indicates a propensity for $\alpha$-structure, and a negative score indicates a propensity for $\beta$ - or extended structure. Residues in fully formed $\alpha$-helices and

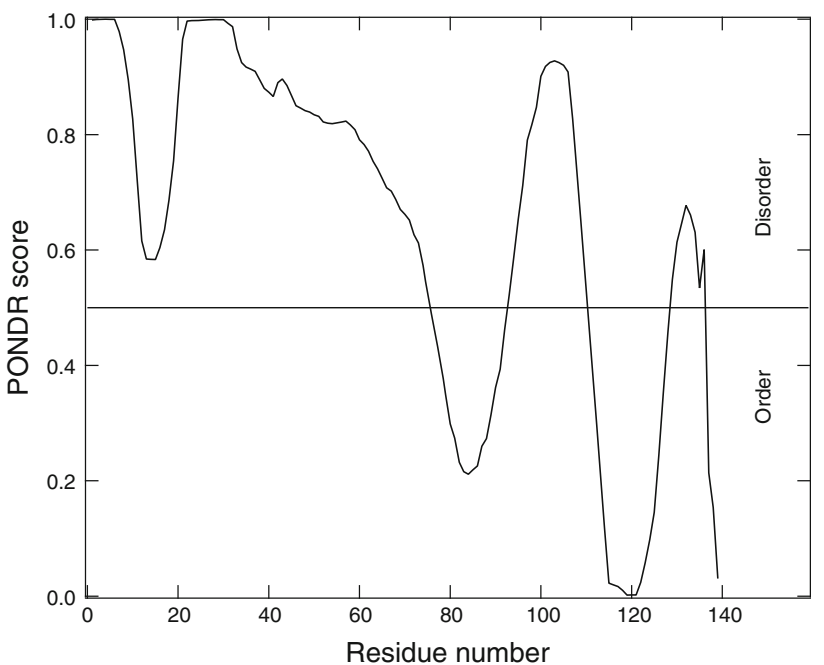

Fig. 3 Predicted regions of order and disorder using PONDR ${ }^{\circledR}$. Sections with PONDR scores of more than 0.5 are predicted to be disordered. An averaging window of nine residues was applied

\begin{tabular}{|c|c|c|c|c|}
\hline MGSSHHHHHH & SSGLVPRGSH & MYRKDKRRQE & PLRQPSPQRG & AWAPELGAAP \\
\hline EEELAALQLG & PTHHECEASP & PHDTLRLTAL & PDYTLTLRRS & PDDIPLMTPN \\
\hline - - ННнНнНнН & . & - & - - - Ннн - - . & - n \\
\hline TITMIPNSLV & GLQTLHPYNT & FAAGFNSTGL & PHSHSTTRV & \\
\hline - . . n . n & $\ldots$ & . & . . . . . . . . & \\
\hline
\end{tabular}

Fig. 4 Structure prediction for hNL3-cyt based on sequence similarity using Jpred 3. Most residues are predicted to be disordered (indicated by dashed line), but three short helical segments are predicted

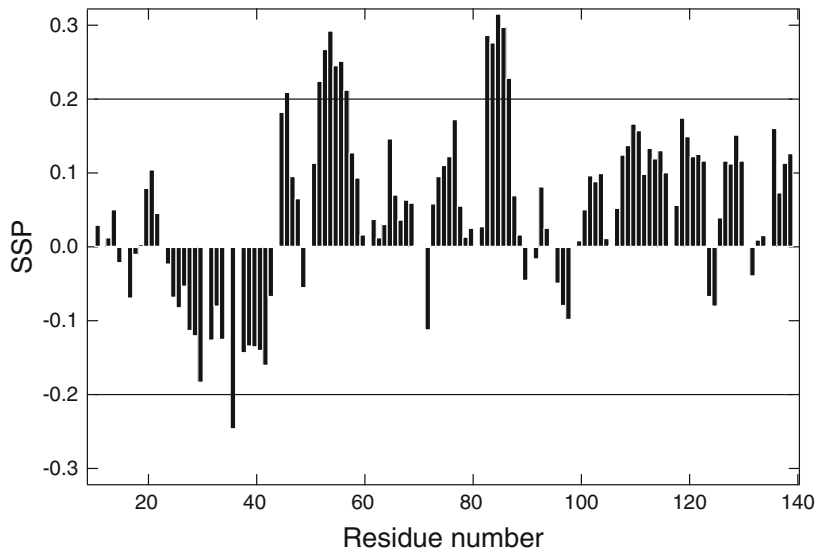

Fig. 5 Secondary structure propensity (SSP) scores calculated using $\mathrm{C}^{\alpha}, \mathrm{C}^{\beta}$ and $\mathrm{H}^{\alpha}$ chemical shifts. Positive and negative values represent a propensity to $\alpha$ - and $\beta$ - or extended structure, respectively. An averaging window of five residues was applied

$\beta$-strands are given scores of +1 and -1 , respectively. As can be seen in Fig. 4, the bulk of hNL3-cyt yields SSP scores within the range of -0.2 to 0.2 , indicating that the sequence has little propensity to assume a stable secondary 
structure. Only two segments have values $>0.2$, residues 51-56 and 82-86.

Our experimental data clearly show that hNL3-cyt does not adopt a well defined tertiary structure, but is intrinsically disordered. The analysis of measured chemical shifts only agrees with the two prediction algorithms used here on one point: the presence of a small stretch with helical propensity around residue 84 . It furthermore agrees with the Jpred 3 prediction that a labile helical segment is present around 52-60. The experimental data do not support the prediction by Jpred 3 of a helical segment around residue 27 , and indicate that the chain adopts an extended structure in this region.

Acknowledgments KW acknowledges a post-doctoral fellowship from the European Molecular Biology Organisation (EMBO). This work was supported by a VIDI grant to F. A. A. M. from The Netherlands Organisation for Scientific Research (NWO), the European Commission VIth Framework Research and Technological Development Program, 'SPINE2-COMPLEXES' Project, under contract No. 031220, the Kimmelman Center for Biomolecular Structure and Assembly, the Divadol Foundation and the Benoziyo Center for Neurosciences. J. L. S. is the Morton and Gladys Pickman Professor of Structural Biology.

Open Access This article is distributed under the terms of the Creative Commons Attribution Noncommercial License which permits any noncommercial use, distribution, and reproduction in any medium, provided the original author(s) and source are credited.

\section{References}

Bai Y, Milne JS, Mayne L, Englander SW (1993) Primary structure effects on peptide group hydrogen exchange. Proteins 17:75-86

Baudouin S, Scheiffele P (2010) Snapshot: neuroligin-neurexin complexes. Cell 141:908 908 e901

Bax A, Clore GM, Gronenborn AM (1990) H-1-H-1 correlation via isotropic mixing of $\mathrm{C}-13$ magnetization, a new 3-dimenstional approach for assigning $\mathrm{H}-1$ and $\mathrm{C}-13$ spectra of $\mathrm{C}-13$-enriched proteins. J Magn Reson 88:425-431

Coggins BE, Venters RA, Zhou P (2004) Generalized reconstruction of n-D NMR spectra from multiple projections: application to the 5-D HACACONH spectrum of protein G B1 domain. J Am Chem Soc 126:1000-1001

Cole C, Barber JD, Barton GJ (2008) The Jpred 3 secondary structure prediction server. Nucleic Acids Res 36:W197-W201

Dalva MB, McClelland AC, Kayser MS (2007) Cell adhesion molecules: signalling functions at the synapse. Nat Rev Neurosci $8: 206-220$

Delaglio F, Grzesiek S, Vuister GW, Zhu G, Pfeifer J, Bax A (1995) NMRPipe: a multidimensional spectral processing system based on UNIX pipes. J Biomol NMR 6:277-293

Dijkstra K, Kroon GJA, van Nuland NAJ, Scheek RM (1994) The COCAH experiment to correlate intraresidue carbonyl, C-alpha, and $\mathrm{H}$-alpha resonances in proteins. J Magn Reson Series A 107:102-105
Gilbert MM, Auld VJ (2005) Evolution of clams (cholinesterase-like adhesion molecules): structure and function during development. Front Biosci 10:2177-2192

Goddard TD, Kneller DG (2004) SPARKY 3. University of California, San Francisco

Grzesiek S, Bax A (1997) A three-dimensional NMR experiment with improved sensitivity for carbonyl-carbonyl $\mathrm{J}$ correlation in proteins. J Biomol NMR 9:207-211

Irie M, Hata Y, Takeuchi M, Ichtchenko K, Toyoda A, Hirao K, Takai Y, Rosahl TW, Sudhof TC (1997) Binding of neuroligins to PSD-95. Science 277:1511-1515

Jamain S, Quach H, Betancur C, Rastam M, Colineaux C, Gillberg IC, Soderstrom H, Giros B, Leboyer M, Gillberg C, Bourgeron T (2003) Mutations of the X-linked genes encoding neuroligins NLGN3 and NLGN4 are associated with autism. Nat Genet 34:27-29

Li C, Han D, Zhang F, Zhou C, Yu HM, Zhang GY (2007) Preconditioning ischemia attenuates increased neurexin-neuroligin1-PSD-95 interaction after transient cerebral ischemia in rat hippocampus. Neurosci Lett 426:192-197

Logan TM, Olejniczak ET, Xu RX, Fesik SW (1993) A general method for assigning NMR spectra of denatured proteins using 3D HC(CO)NH-TOCSY triple resonance experiments. J Biomol NMR 3:225-231

Marion D, Kay LE, Sparks SW, Torchia DA, Bax A (1989) 3-Dimensional Heteronuclear NMR of N-15-labeled proteins. J Am Chem Soc 111:1515-1517

Markley JL, Bax A, Arata Y, Hilbers CW, Kaptein R, Sykes BD, Wright PE, Wuthrich K (1998) Recommendations for the presentation of NMR structures of proteins and nucleic acids. IUPAC-IUBMB-IUPAB Inter-union task group on the standardization of data bases of protein and nucleic acid structures determined by NMR spectroscopy. J Biomol NMR 12:1-23

Marsh JA, Singh VK, Jia Z, Forman-Kay JD (2006) Sensitivity of secondary structure propensities to sequence differences between alpha- and gamma-synuclein: implications for fibrillation. Protein Sci 15:2795-2804

Panchal SC, Bhavesh NS, Hosur RV (2001) Improved 3D triple resonance experiments, $\mathrm{HNN}$ and $\mathrm{HN}(\mathrm{C}) \mathrm{N}$, for $\mathrm{HN}$ and $15 \mathrm{~N}$ sequential correlations in $(13 \mathrm{C}, 15 \mathrm{~N})$ labeled proteins: application to unfolded proteins. J Biomol NMR 20:135-147

Paz A, Zeev-Ben-Mordehai T, Lundqvist M, Sherman E, Mylonas E, Weiner L, Haran G, Svergun DI, Mulder FAA, Sussman JL, Silman I (2008) Biophysical characterization of the unstructured cytoplasmic domain of the human neuronal adhesion protein neuroligin 3. Biophys J 95:1928-1944

Romero P, Obradovic Z, Li X, Garner E, Brown C, Dunker AK (2001) Sequence complexity of disordered protein. Proteins 42:38-48

Sattler M, Schleucher J, Griesinger C (1999) Heteronuclear multidimensional NMR experiments for the structure determination of proteins in solution employing pulsed field gradients. Prog Nucl Magn Reson Spectrosc 34:93-158

Uversky VN, Gillespie JR, Fink AL (2000) Why are "natively unfolded" proteins unstructured under physiologic conditions? Proteins 41:415-427

Zeev-Ben-Mordehai T, Rydberg EH, Solomon A, Toker L, Auld VJ, Silman I, Botti S, Sussman JL (2003) The intracellular domain of the Drosophila cholinesterase-like neural adhesion protein, gliotactin, is natively unfolded. Proteins 53:758-767 